\title{
Editorial
}

\section{Covid-19 vaccines for children}

Sri Lanka Journal of Child Health, 2022; 51(1): 1-3

DOI: http://dx.doi.org/10.4038/sljch.v51i1.10006

(Key words: Covid-19 vaccine, Children)

In the last few months of evident uncertainty regarding the likely progression of SARS-CoV-2, there is considerable apprehension and intense anxiety amongst the general populace of our country. With the added complication of mutant variants, all designated by the letters of the Greek alphabet, the melting pot actually boils and even overflows. In addition to scientific data and proper pedagogic assessments, there is substantial misinformation and disinformation, particularly regarding the Covid-19 vaccines, especially in the social media. Some totally unsubstantiated allegations, stipulations, postulations and prophesies of gloom, are being widely circulated. People who flatly refuse to take the vaccine, those who are hesitant to receive it and confirmed anti-vaxxers, are having a field day in trying to dissuade the general public from taking the vaccine.

This situation is of particular concern when such false proclamations tend to discourage children being given the Covid-19 vaccine. In Sri Lanka, firstly it was the front-line healthcare workers, the tri-forces and the police who were prioritized to receive the vaccine. Then came the over 60 -yearolds, especially those who have on-going comorbid diseases. Following that, young adults and those under 60 years with coexisting other diseases were lined up. Then the authorities started to vaccinate all those from 19 to 60 years of age, followed by students in the higher classes of 15 to 19 years of age and those over 12 years with coexistent diseases. The latest initiative of the government, based on medical advice, is to vaccinate all children from 12 to 15 years of age, starting from $07^{\text {th }}$ January 2022 .

The anti-vaxxers and their ilk have put forward many 'problems and complications' of the vaccines to dissuade others from taking the vaccine and also desist from giving it to their children. The antivaxxers blew up, out of all proportions, the quaint issue of vaccine-induced immune thrombotic thrombocytopenia (VITT) that has been reported after Covid-19 vaccinations. True enough, it could occur but it is a very rare phenomenon. An article published in the New England Journal of Medicine in October 2021 estimated these clotting problems to occur in about 1 in 50,000 of those under 50 years of age who have received the Oxford-AstraZeneca vaccine $^{1}$. Then came the canard of reduced sexual prowess and sub-fertility induced by the vaccine in young people. This is a complete myth and there is no scientific evidence whatsoever for this contention. This 'rumour' totally discouraged a lot of youth, young people and young adults from taking the vaccine.

The most recent adverse effect of the Covid-19 vaccines that has been brought to light is the occurrence of myocarditis and to a lesser extent, pericarditis. These inflammatory complications seen in young adults and older children are extremely rare. An article in a pre-print journal medRxiv, posted on $05^{\text {th }}$ December 2021, estimated that these complications occurred in 297 out of a total of $19,740,741$ doses of the m-RNA vaccines administered $^{2}$. This gives a rate of about 15 per million doses. Symptomatic myocarditis is relatively mild and does not cause long-term cardiac problems. Many scientific articles that have looked at this complication have not reported any deaths. In fact, Covid-19 disease itself could cause myocarditis, with an incidence of around 28 per cent of all hospitalised patients with Covid-19. The considered opinion of the scientific community is that the complication rate of the disease itself is much more than the adverse effects such as myocarditis and pericarditis that could occur with the vaccine.

Yet for all that, one must always keep in mind that these complication rates cannot be superimposed on to given individuals. In other words, if for example, the hypothetical incidence is one in fifty thousand, when one looks at a single person who is to be given the vaccine, we have no way of knowing whether that individual may or may not be the one to get the complication. The scientifically quoted rates only confirm their rarity or higher incidence and prevalence, as the case may be. Safe, effective vaccines against Covid-19 are also needed in children younger than 12 years of age. There are some recent developments regarding the feasibility of vaccinating children under 12 years. A phase 1, dose-finding study and an ongoing phase 2-3 randomized trial are in place to investigate the safety, immunogenicity, and efficacy of two doses of the BNT162b2 Pfizer vaccine administered 21 days apart to children 6 months to 11 years of age.

From the results of that study, in a scientific paper published in the New England Journal of Medicine on $06^{\text {th }}$ January 2022, the researchers have shown that a Covid-19 vaccination regimen consisting of 
two 10-microgram doses of the Pfizer vaccine, administered 21 days apart, was found to be safe, immunogenic and efficacious in children 5 to 11 years of age ${ }^{3}$. It is noteworthy that the 10 -microgram dose is one third of the adult dose of 30 microgram and that two doses that are 21 days apart are needed. In addition, the United States Centres for Disease Control and Prevention's (CDC's) Morbidity and Mortality Weekly Report details the preliminary safety findings for the administration of PfizerBioNTech coronavirus disease 2019 (Covid-19) vaccine among children aged 5 to 11 years ${ }^{4}$. To characterise safety of the vaccine in children aged 5 to 11 years, the $\mathrm{CDC}$ reviewed adverse events after receipt of Pfizer-BioNTech Covid-19 vaccine reported to the Vaccine Adverse Event Reporting System (VAERS), which is a passive vaccine safety surveillance system co-managed by CDC and United States Food and Drug Administration, from November 3 to December 19, 2021 ${ }^{4}$. Approximately 8.7 million doses of Pfizer-BioNTech Covid-19 vaccine were administered to children aged 5 to 11 years during this period. They found that 97.6 per cent of the adverse reactions reported were not serious. There were 11 children who developed myocarditis/pericarditis and all recovered with no long-term cardiac problems.

Yet for all that, there is some disturbing information that has been published regarding the Omicron variant in the journal Nature on $23^{\text {rd }}$ December $2021^{5}$. From the time that the Omicron mutant was detected in November 2021 in Botswana and South Africa, it seems to have spread widely. It is projected to become dominant worldwide, especially in view of its augmented transmissibility. The lineage is characterized by the presence of over 30 mutations in the spike protein, which is suspected to enhance viral fitness and allow antibody evasion. The report documents the resistance shown by an Omicron isolate from Belgium, in a traveller returning from Egypt. They examined its sensitivity to 9 monoclonal antibodies (mAbs) clinically approved or in development, and to antibodies present in 115 sera from Covid-19 vaccine recipients or convalescent individuals. The isolate was totally or partially resistant to neutralization by all mAbs tested. Sera from Pfizer or AstraZeneca vaccine recipients, sampled 5 months after complete vaccination, barely inhibited the isolate. Sera from Covid-19 convalescent patients collected 6 or 12 months after symptomatic natural infection with Covid-19 displayed low or no neutralizing activity against Omicron. However, administration of a booster Pfizer vaccine dose as well as vaccination of previously infected individuals, generated a significant anti-Omicron neutralizing response. It has been suggested that Omicron escapes most therapeutic monoclonal antibodies and also to a large extent, vaccine-elicited antibodies. Omicron remains however neutralized by antibodies generated by a booster vaccine dose, given as a third dose.

Currently in Sri Lanka, only a single dose of Pfizer vaccine is to be given to children and young people. This position will need to be re-evaluated and revisions made thereof, if and when more scientific information becomes available. We are continuously learning about Covid-19 on the go and nothing is written in stone to stay like that forever. Flexibility, with decisions being made on robust scientific grounds, would be the way to go in the future. As the President of the Royal College of Paediatrics and Child Health of the UK, Dr Camilla Kingdon so graphically pointed out in a recent communique, we are being tried on the perpetual need to "go yet another mile" . It is up to all of us to respond.

\section{References}

1. Pavord S, Scully M, Hunt BJ, Lester W, Bagot C, Craven B, et al. Clinical features of vaccine-induced immune thrombocytopenia and thrombosis. New England Journal of Medicine 2021; 385: 1680-9.

https://doi.org/10.1056/NEJMoa2109908 PMid: 34379914

2. Buchan SA, Seo CY, Johnson C, Alley S, Kwong JC, Nasreen S, et al. Epidemiology of myocarditis and pericarditis following mRNA vaccines in Ontario, Canada: by vaccine product, schedule and interval. medRxiv 2021.12.02.21267156; https://doi.org/10.1101/2021.12.02.21267 156

3. Walter EB, Talaat KR, Sabharwal C, Gurtman A, Lockhart S, Paulsen GC, et al. Evaluation of the BNT162b2 Covid-19 vaccine in children 5 to 11 years of age. New England Journal of Medicine 2022; 386: $35-46$.

https://doi.org/10.1056/NEJMoa2116298 PMid: 34752019 PMCid: PMC8609605

4. Hause AM, Baggs J, Marquez P, Myers TR, Gee J, Su JR, et al. Covid-19 vaccine safety in children aged 5-11 years United States, November 3-December 19, 2021. Available from:

https:/www.cdc.gov/mmwr/volumes/70/ wr/mm705152a1.htm. Accessed 11 January 2022. https://doi.org/10.15585/mmwr.mm70515 2al

PMid: 34968370 PMCid: PMC8736274 
5. Planas D, Saunders N, Maes P, GuivelBenhassine F, Planchais C, Buchrieser J, et al Considerable escape of SARS-CoV-2 Omicron to antibody neutralization. Nature. Available from:

https://www.nature.com/articles/d41586021-03827-2. Published 23 $3^{\text {rd }}$ December 2021. Accessed $11^{\text {th }}$ January 2022. https://doi.org/10.1038/s41586-02104389-z
6. Update from RCPCH President - 14 January 2022. Available from: https://mail.yahoo.com/d/folders/1/messag es/195526. Accessed $16^{\text {th }}$ January 2022.

B J C Perera orcid.org/0000-0001-7789-8793 Joint Editor

The author declares that there are no conflicts of interest

Open Access Article published under the Creative Commons Attribution CC-BY (c) (i) 